\title{
Analysis of Multi-Level Inverter For 7-Level Architecture using MATLAB Simulink
}

\author{
Hedaytullah Khan ${ }^{1}$, Ameen Uddin Ahmad ${ }^{2}$ \\ M.Tech Scholar, EECE Department, Al-Falah University, Faridabad, Haryana, India ${ }^{1}$ \\ Assistant Professor, EECE Department, Al-Falah University, Faridabad, Haryana, India ${ }^{2}$
}

\begin{abstract}
This thesis describes the detailed study of Multi-level Inverters for 5-level and 7-level Multi-level inverters and an improvement is seen in 7-level harmonic distortion by a significant amount. Numerous industrial applications have begun to require higher power apparatus in recent years. Some medium voltage motor drives and utility applications require medium voltage and megawatt power level. For a medium voltage grid, it is troublesome to connect only one power semiconductor switch directly. As a result, a multilevel power converter structure has been introduced as an alternative in high power and medium voltage situations. The THD in $7-$ level is about $28 \%$.
\end{abstract}

Keywords: MLI, Cascaded, THD, 5-level, 7-level

\section{INTRODUCTION}

The idea of multilevel converters has been presented since 1975. The term multilevel started with the three-level converter. In this manner, a few multilevel converter topologies have been produced. Be that as it may, the rudimentary idea of a multilevel converter to accomplish higher power is to utilize a progression of power semiconductor switches with a few lower voltage dc sources to play out the power change by combining a staircase voltage waveform. Capacitors, batteries, and sustainable power source voltage sources can be utilized as the multiple DC voltage sources. The replacement of the power switches aggregate these multiple DC sources with a specific end goal to accomplish high voltage at the yield; be that as it may, the appraised voltage of the power semiconductor switches depends just upon the rating of the dc voltage sources to which they are associated.

\section{SIMULATION RESULTS}

In this chapter, Implementation and results are presented. The model for 5 level Multi-level Inverter is shown in Figure 1. It is a cascaded type of multi-level inverter using MOSFET.

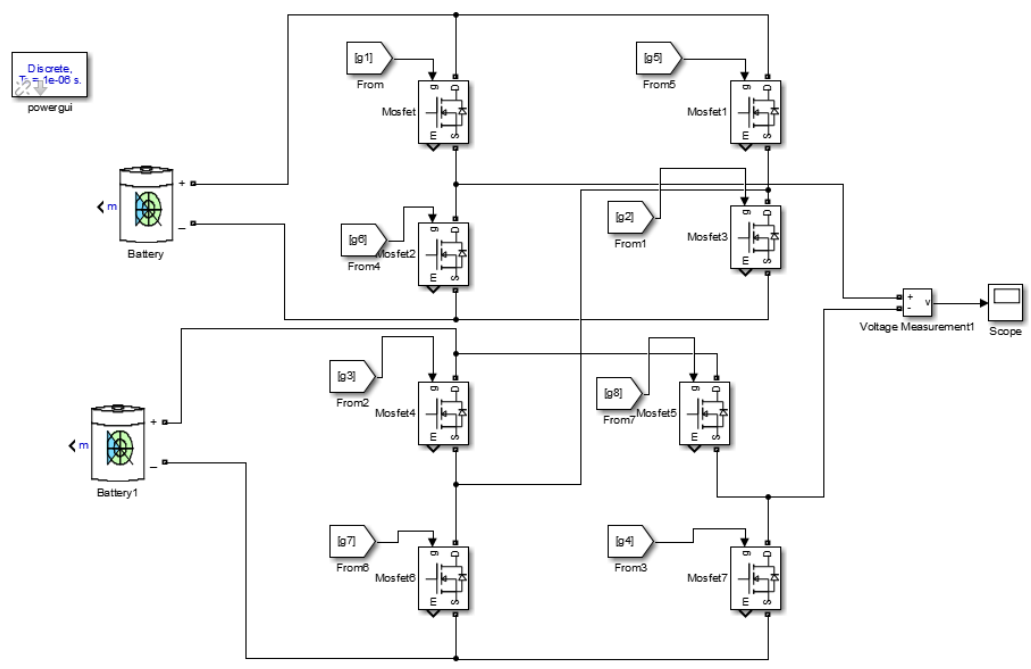

Figure 1: Multi-level Inverter for 5 -level

For controlling of the switches techniques used is based on Sinusoidal Pulse width modulation which is generally known as SPWM. The control diagram is given in Figure 2. 
International Journal of Innovative Research in Electrical, Electronics, Instrumentation and Control Engineering

Vol. 6, Issue 8, August 2018

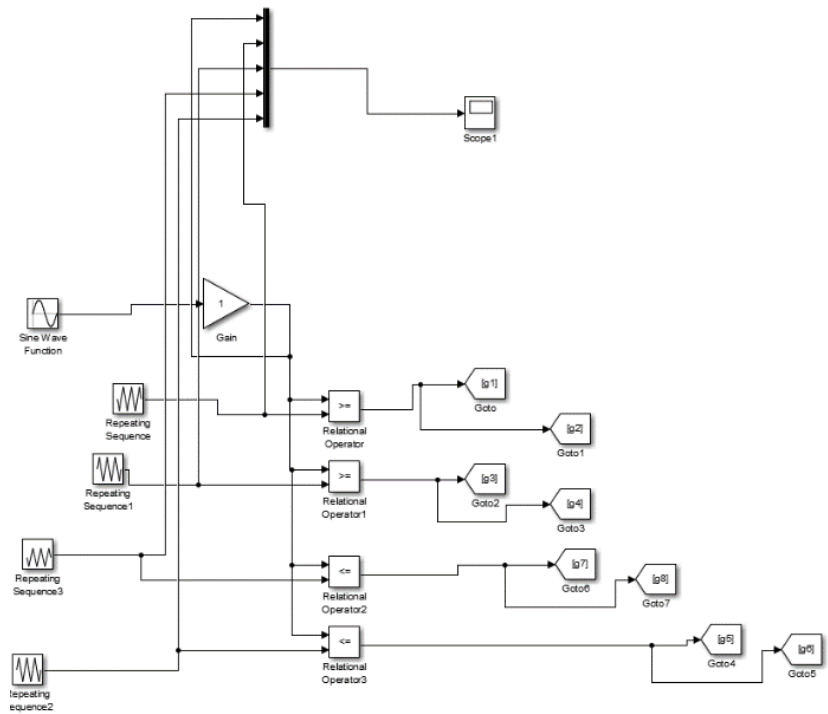

Figure 2: Controlling of Converter 5 level

Figure 3 shows the output waveform, and figure 5 shows the waveform for FFT analysis of the same and Figure 4.6 shows the FFT analysis.

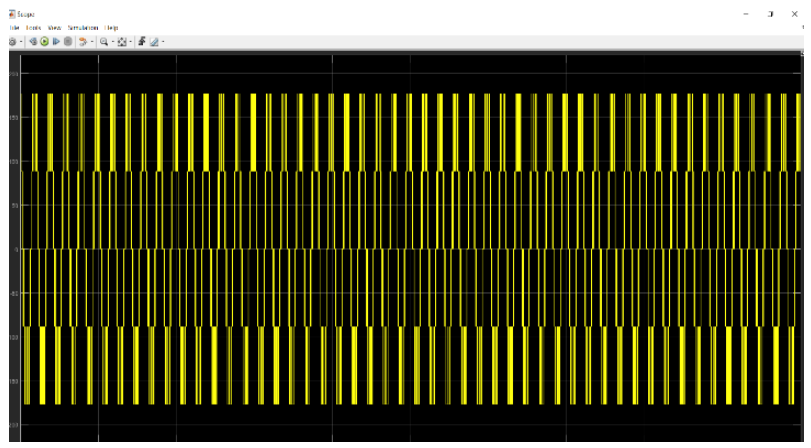

Figure 4: Waveform output

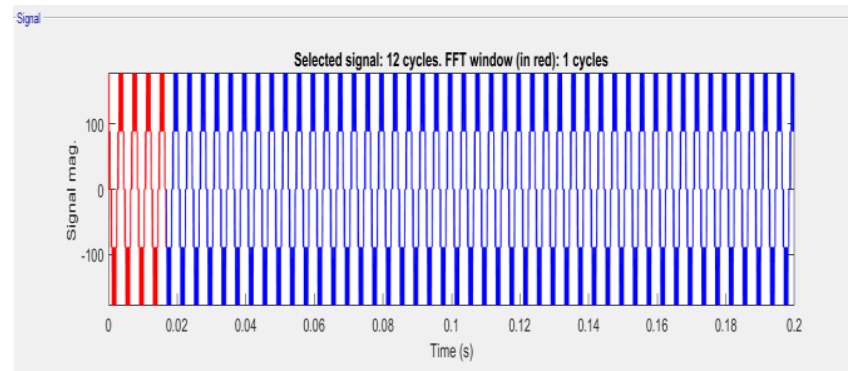

Figure 5: Waveform output for FFT analysis

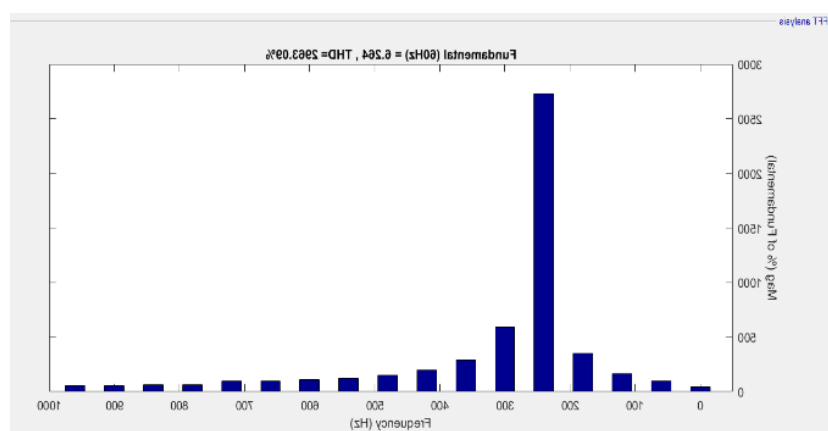

Figure 6: FFT analysis of 5 level 
International Journal of Innovative Research in Electrical, Electronics, Instrumentation and Control Engineering

Vol. 6, Issue 8, August 2018

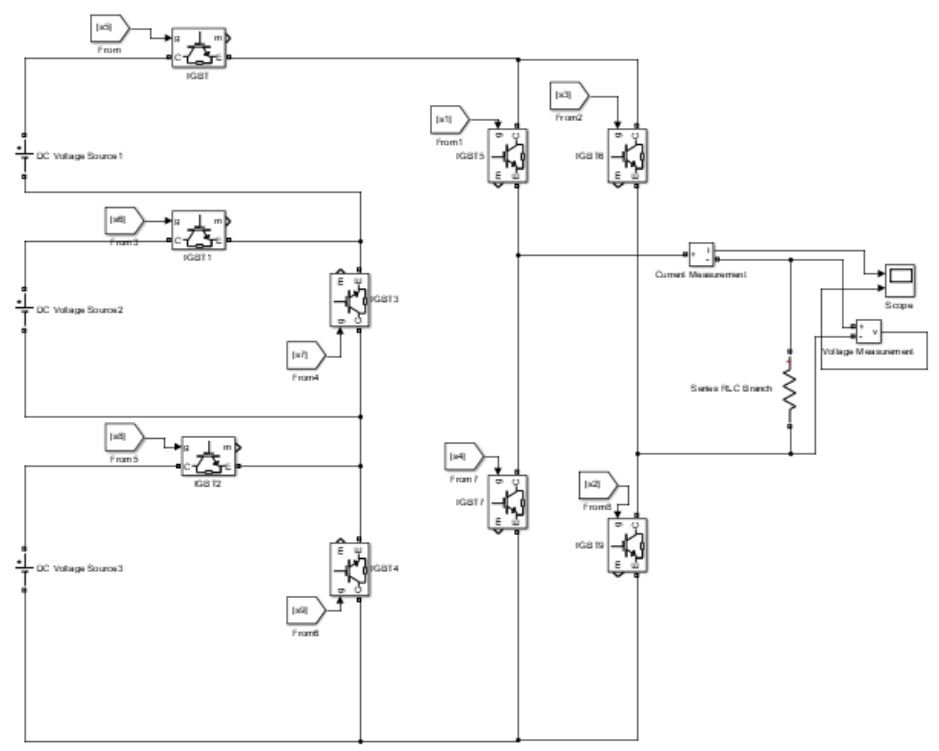

Figure 7: Proposed Model for 7 -level

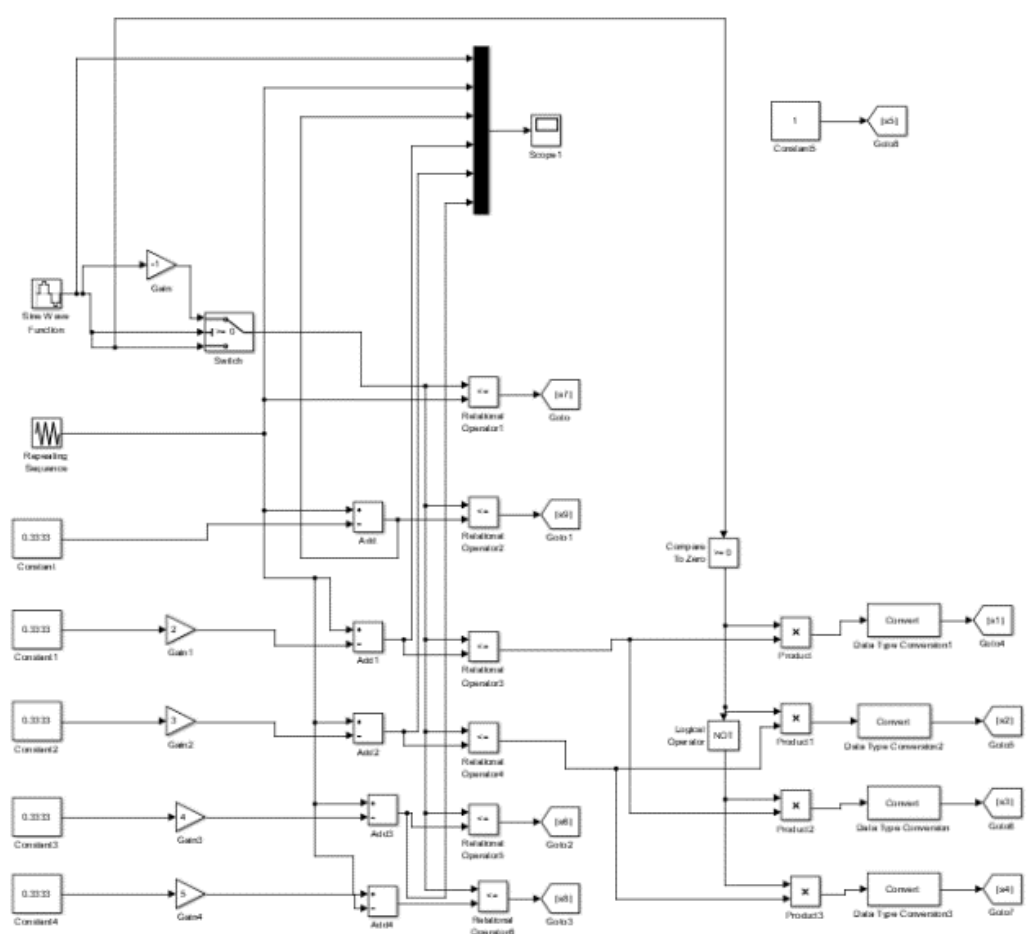

Figure 8: Control Strategy for proposed model

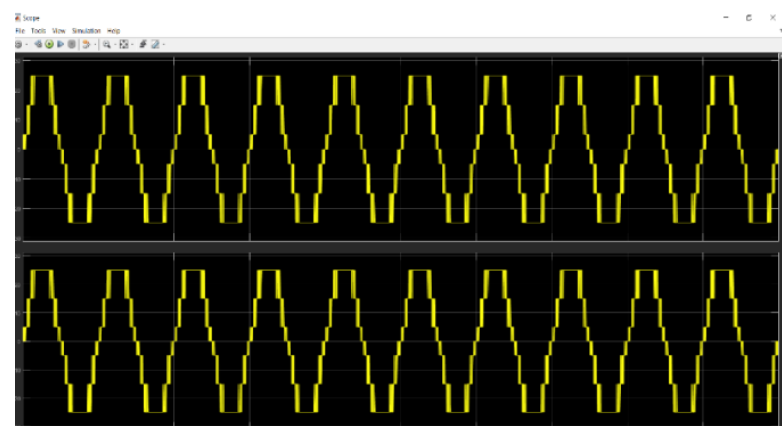

Figure 9: Waveform output of proposed 7-level 


\section{International Journal of Innovative Research in Electrical, Electronics, Instrumentation and Control Engineering}

Vol. 6, Issue 8, August 2018

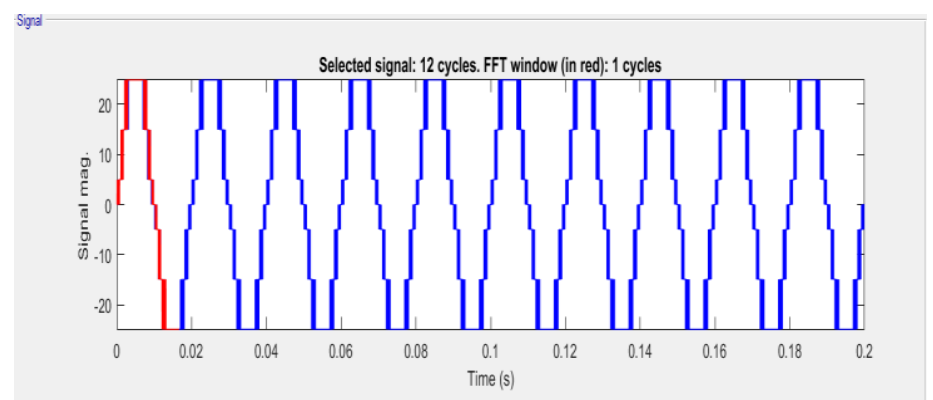

Figure 10: Waveform output for FFT Analysis proposed 7-level

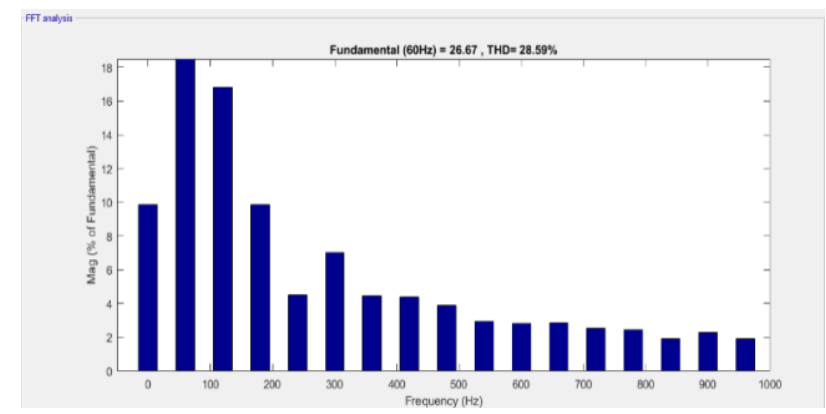

Figure 11: FFT Analysis of Proposed 7-level

\section{CONCLUSION}

This paper has provided a brief summary of multilevel inverter circuit topologies 5-level and 7-level) and their analysis. It is seen that in 7-level inverter THD is minimum when compared to the base paper results as shown in Figure 12. The THD of 7-level inverter is $28.59 \%$.

\begin{tabular}{|c|c|c|}
\hline \multirow{2}{*}{ M.I } & \multicolumn{2}{|c|}{ Proposed CO-APOD } \\
\cline { 2 - 3 } & THD\% & Voltage \\
\hline 1.0 & 31.76 & 189.60 \\
\hline 0.9 & 32.76 & 180.30 \\
\hline 0.8 & 35.58 & 164.60 \\
\hline 0.7 & 40.64 & 141.40 \\
\hline
\end{tabular}

Figure 12: comparison to base results[1]

\section{REFERENCES}

[1] Kureve D. Teryima1*, Agbo O. David2 and Samuel T. Awuhe3, “THD Analysis of an Overlapping Carrier Based SPWM For a 5-Level Cascaded H-bridge Multilevel Inverter”, International Journal of Advanced Science and Technology Vol.87 (2016), pp.47-56.

[2] jigar N. Mistry and Pratik H. Savsani, "Flying Clamped Capacitor Multilevel inverter in variable Frequency Drive", international journal of Advanced Research in Computer and Communication Engineering, vol. 2, issue 9, September 2013, pp. 3697-3701.

[3] S. Krishnapriya and Unnikrishnan 1. "Multilevel inverter Fed induction Motor Drives", international journal of Research in Engineering and Technology (ijRET), volume 04, issue 09, September2015, pp. 60-64.

[4] Fang Zheng Peng, "A Generalized Multilevel inverter Topology with Self voltage Balancing”, iEEE Transactions on industry Uses, vol. 37 , No. 2, March/April 2001, pp. 611-618.

[5] Dhana Prasad Duggapu, Satya venkata Kishore Pulavarthi and Swathi Nulakajodu, "Comparison between Diode Clamped and H- Bridge Multilevel inverter (5 to 15 odd levels)”, international journal of Emerging Trends in Electrical and Electronics (ijETEE), vol. 1, issue. 4, March2013, pp. 66-78.

[6] http://engineering.electrical-equipment.org/electrical-distribution/multilevel-inverter-topologies.html

[7] T.Porselvi and Ranganath Muthu, "Comparison of Cascaded H-Bridge, Neutral Point Clamped and Flying Capacitor Multilevel inverters using Multirequired carrier PWM", researchgate.net/publication/254048552, December 2011.

[8] Mohammad Farhadi Kangarlu, Student Member, iEEE, and Ebrahim Babaei, Member, iEEE, "A Generalized Cascaded Multilevel inverter Using Series Connection of Sub multilevel inverters " iEEE transactions on power electronics, vol. 28, no. 2, February 2013 pp: $625-636$.

[9] Farid Khoucha, Soumia Mouna lagoun, Khoudir Marouani, Abdelaziz Kheloui, and Mohamed El Hachemi Benbouzid, Senior Member, iEEE, "Hybrid Cascaded H-Bridge Multilevel-inverter induction-Motor-Drive Direct Torque Control for Automotive Uses" iEEE transactions on energy conversion, vol. 28, no.3, September 2013 pp: 43-651.

[10] Xiaotian Zhang, Student Member, iEEE, and joseph W. Spencer, "Study of Multi-sampled Multilevel inverters to improve Control Performance"'iEEE transactions on power electronics, vol. 27, no. 11, November 2012 pp:4409-4416. 


\section{IJIREEICE \\ International Journal of Innovative Research in Electrical, Electronics, Instrumentation and Control Engineering}

Vol. 6, Issue 8, August 2018

[11] Marcelo C. Cavalcanti, Alexandre M. Farias, Kleber C. Oliveira, Francisco A. S. Neves, and joão 1. Afonso, "Eliminating leakage Currents in Neutral Point Clamped inverters for Photovoltaic Systems", iEEE Trans. On industrial Electronics, vol. 59, No. 1, pp. 435-443, jan 2012.

[12] jeffrey Ewanchuk, john Salmon, and Behzadvafakhah, "A Five-/Nine level Twelve-Switch Neutral-Point-Clamped inverter for High-Speed Electric Drives”, iEEE Trans On industry Uses, vol. 47, No. 5, pp. 2145-2153, Sept/Oct 2011.

[13] Amit Kumar jain, and v. T. Ranganathan,"vCE Sensing for iGBT Protection in NPC Three level Converters-Causes For Spurious Trippings and Their Elimination”, iEEE Trans. On Power Electronics, vol. 26,No. 1, pp. 298-307, jan 2011.

[14] Robert Stala, "Application of Balancing Circuit for DC-link voltages Balance in a Single-Phase Diode-Clamped inverter With Two Three-level legs", iEEE Trans On industrial Electronics, vol. 58, No. 9, pp. 4185-4195, Sept 2011

[15] M.Trabelsi, and 1.Ben-Brahim, "Development Of A Grid Connected Photovoltaic Power Conditioning System Based On Flying Capacitors inverter", 8th international Multi-Conference on Systems, Signals and Devices, pp. 1-6, May 2011.

[16] Wahidah Abd. Halim and Nasrudin Abd. Rahim, "FPGA - Based Pulse- Width Modulation Control For Single-Phase Multilevel inverter", iEEE First Conference on Clean Energy and Technology, CET, pp.57-62, 2011.

[17] Sridhar R. Pulikanti, Mohamed S. A. Dahidah, and vassilios G. Agelidis, "voltage Balancing Control of Three-level Active NPC Converter Using SHE-PWM", iEEE Trans. On Power Delivery, vol. 26, No. 1, pp. 258-267, jan. 2011.

[18] j. Rodriguez, j. S. lai and F. Z. Peng, -Multilevel inverters: Survey of Topologies, Controls, and Uses, $\|$ iEEE Transactions on industry Uses, vol. 49, no. 4, Aug. 2002, pp. 724-738.

[19] A. Bendre and G. venkataramanan, -Neutral current ripple minimization in a three-level rectifier,॥ iEEE Trans. ind. Applicat. , vol. 42, no. 2, pp. 582-590, Mar. 2006.

[20] Baoming Ge, Fang Zheng Peng, Aníbal T. de Almeida, and Haitham Abu-Rub, —An Effective Control Technique for Medium-voltage HighPower induction Motor Fed by Cascaded Neutral-Point-Clamped inverterl, iEEE Trans On industrial Electronics, vol. 57, No. 8, pp. 2659-2668, Aug 2010.

[21] Arash A. Boora, Alireza Nami, Firuz Zare, Arindam Ghosh, and Frede Blaabjerg, —voltage-Sharing Converter to Supply Single-Phase Asymmetrical Four-level Diode-Clamped inverter With High Power Factor loadsl, iEEE Trans On Power Electronics, vol. 25, No. 10,Pp. 25072520, Oct 2010.

[22] C. Attaianese, M. Di Monaco, and G. Tomasso, - Three-Phase Three-level Active NPC Converters for High Power Systeml, international Symposium on Power Electronics, Electrical Drives, Automation and Motion, pp. 204-209, Speedam 2010.

[23] Amit Kumar jain, and v. T. Ranganathan, - vCE sensing for iGBT Protection in NPC Three

level Converters-Causes For Spurious Trippings and Their Elimination\|, iEEE Trans On Power Electronics, vol. 26, No. 1, pp. 298-307, jan 2011. 